\title{
Beauty Pageants, Controverted Decisions and Emotional Outpour: An Analysis of Social Media Posts on GHANA'S MOST BEAUTIFUL
}

\author{
Andy Ofori-Birikorang \\ Department of Communication and Media Studies, University of Education, Winneba \\ Ama Boatemaa Appiah-Kubi \\ Cathy Hughes School of Communication, Culture and Media Studies, Howard University \\ Akosua Asantewaa Anane \\ Department of Communication and Media Studies, University of Education, Winneba \\ Yvonne Dedzo \\ Department of Communication and Media Studies, University of Education, Winneba
}

\begin{abstract}
Since its emergence, beauty pageantry as a cultural even and entertainment programme has been predominantly characterized as controversial and an unwelcome social venture. Scholars like Cohen, Wilk and Stoeltje (1996) reiterate this by arguing that beauty pageants have become sites of controversy and resistance. In Ghana, most of these controversies take the form of audience uproar and outburst on social media, especially at the end of the contest when expectations are not met. Following the excessive amount of data social media generates on the beauty contest, it has become all-important for researchers to focus our attention on interrogating the posts shared by audiences as well as the emotions seeded in them. The study, therefore, examines social media posts of audiences on an indigenous beauty pageant in Ghana, Ghana's Most Beautiful (GMB). The paper adopts the Reader-Response theory, Philosophical Hermeneutics and Ekman and Friesen's six basic emotions to interrogate Facebook users' posts on the coronation of the 2017 and 2018 beauty Queens, Zeinab and Abena. Using qualitative content analysis, cyber ethnographic and thematic analysis of several purposively sampled Facebook posts, the study revealed that through emotional outpour of anger, disgust, sadness, surprise, and happiness, audience raised contemptuous and social issues such as corruption, aspersions, signification/ethnocentrism, and objectification. Withal, they also highlighted issues like glorification, and divination. Again, the study found that the beauty queens, through users' posts were represented as commodities, assertive, purposeful, heroic and intelligent. The study concludes that organizers of GMB re-consider a total restructuring of the pageant into one that embraces cultural differences devoid of commodification and oppression of women.
\end{abstract}

Keywords: Ghana's Most Beautiful, Beauty pageants, audience emotions, emotional display, social media DOI: $10.7176 / \mathrm{NMMC} / 97-05$

Publication date:August $31^{\text {st }} 2021$

\section{Introduction}

Beauty pageants are global phenomenon and in recent times have become increasingly popular with hundreds of spectators ranging from small local groups to large television audiences (Crawford, et al., 2008). Although there is little documentation of the spread of beauty pageantry, it is evident that it has proliferated and become extremely popular (Cohen, Wilk \& Stoeltje, 1996; Crawford et al., 2008). For example, reports show that Miss World Pageantry is held annually in 104 countries and it is the most watched annually televised event in the world (Crawford et al., 2008). This proliferation is partly attributed to its acceptance as a form of entertainment by many audiences across the globe (Banet-Weiser, 1999). According to Crawford et al. (2008), Beauty pageants present an ideology of creating competition in which women compete with each other over who is the most traditionally and physically attractive to a set of judges. Hinjosa and Carle (2016), however, assert that Beauty pageants emphasize public speaking skills, poise under pressure, engage in the solicitation of financial support, and promote the development of self-confidence. Thus, contestants of female beauty pageants are expected to engage in performances beyond their looks in order to come out as winners. Hamashima (2012) reiterate this when she avows that there has been a shift from beauty in the pageant competitions to a broader concentration on scholarship and education, cultural preservation, cultural awareness, gender equality, and health among others.

In Ghana, for example, Beauty pageants have become powerful means for promoting Ghana's diverse culture. Ghana's Most Beautiful beauty pageantry, a flagship program of TV3 network over the years, has become a platform where female contestants represent their various regions and strive to portray their rich indigenous culture (Koomson, 2016). The pageantry places great emphasis on cultural relevance instead of 
physical beauty. The Ladies who participate in the reality show are required to depict the unique traditional culture and values related to the various ethnic groups of the regions they represent in the country and, as well, promote national unity among the regions and its people, their culture and values (Koomson, 2016). Even though the beauty pageants are diverse and varied as their respective cultural and historical tends to be, they are all designed in similar ways to exhibit the values, concepts and behaviours that exist at the center of a group's sense of itself and shows values of morality, gender and place. It has become a forum where national identity and culture can be made public and visible (Cohen, Wilk \& Stoeltje, 1996).

That notwithstanding, beauty pageants persistently have been sites of controversy and resistance even after their proliferation to different parts of the world (Crawford et al., 2008). They evoke controversy over qualities that should count in a competition, how women should act and what the outcome means or should be. It is not surprising, therefore, that the world has witnessed diverse outbursts on Beauty pageants. Research has it that there have been numerous public uproars and protests on Beauty pageants in different parts of the world. In 1996 for example, the Miss World pageant in Bangalore led to public unrests, riots and social upheaval (Oza, 2001). Similar and even far worse situation occurred in 2002 in Nigeria when about 200 people were killed (Crawford, et al., 2008). Evidently, most of these controversies, especially in developing countries reflect competing discourses of femininity, nationalism, morality, commodification and modernization (Ahmed-Ghosh, 2003; Oza, 2001). However, in Ghana, the controversies usually revolve around the quality and decisions made by judges usually during the grand finales when the most popular contestant of the audience does not emerge the winner. In recent times, social media has become the platform for the contestations of such controversies. As argued by many scholars, social media sites, over decades now have become platforms where billions of people across the globe freely conduct activities, including creating and sharing of content and expressing themselves. Social media has become the most preferred medium for many to share information, both positive and negative (Lukes, 2010). It is not surprising, therefore, that usually, after each grand finale of Ghana's Most Beautiful audience troop to social media, specifically, Facebook to express their perceptions and emotions on the results of the context. Important in these numerous social media controversies and comments are audience portrayals of the beauty queens and contestants with the consequential emotional ramifications of such portrayals. It is, therefore, imperative to investigate the dominant issues that emerge out of these numerous controversies, the emotions that are produced and significantly, how the beauty queens have been portrayed by the posts.

\section{Rationale}

Several studies, including audience engagement of media texts, have been conducted on beauty pageants in Africa and across the globe. Most of the studies include: the portrayal of beauty queens by the media; feminist critic of beauty pageants; impact of beauty pageants on society; and, the perceptions of audiences on beauty pageants (Barnes, 1994; Balogun, 2012; Crawford et al., 2008; Delfinado, 2016; Dennis, 2018; Hamashima, 2012; King-O’Riain, 2008).

Crawford et al. (2008) through focus groups and semi-structured interviews did a study that interrogated the attitude of Nepali women on beauty pageants. The study revealed that even though Nepali women believed in the possibility of beauty contests in empowering women and facilitating development in Nepal, they had their own reservations about how the pageant commodifies and objectifies women. In trying to understand the role of cultural production within the globalizing of beauty pageants, King-O'Riain (2008) also conducted a study that revealed that beauty pageants are interesting cultural production sites that provide global evidence of oppression, commodification and consumption even within the pageant itself. Notably, they are also sites where identities are produced. Through qualitative content analysis of existing studies on beauty pageants and surveys among Filipino youth and young adults, Delfinado (2016) also investigated how beauty pageants affect the emotions, value system and identity formation of those who are fascinated about it. The study revealed that even though beauty pageants impose on people a particular standard of what an ideal woman should be and as well sexualize and objectify contestants, many Filipinos see beauty pageant as a symbol of Filipino culture. The study, therefore, concludes that beauty pageants embrace a more diverse form of beauty, where every form of beauty is accepted and celebrated instead of sticking to a boxed form of standard.

Balogun (2012) also investigated beauty pageants as public enactments of cultural production that constitute presentations of cultural identities and struggles of cultural meaning. In this study, the author demonstrates beauty pageants as sites for the production of nationalism through negotiations of belonging and exclusion and through that reveals how multiple strands of nationalism may be consolidated even while in tension. Hamashima (2012), focusing on Miss Samoa, also looks at the cultural and social relevance of the pageant. Through interviews and surveys, the study found the pageantry as a popular phenomenon for its entertainment value rather than cultural relevance. The Miss Samoa pageant has been acknowledged as an agent of empowerment for individual women but not necessarily influential on a larger social scale. The results also suggested that the pageantry should be integrated into Samoa society as more of an indigenous pageant than a beauty pageant. In order to encourage future development, the Miss Samoa pageant would need to prioritize the indigenous as the 
paramount focus.

Within the extant of literature reviewed, it has become evident that minimal studies have been done on beauty pageants with particular emphasis on posts shared by audiences on social media, especially after the end of a contest when a winner is crowned. Also, huge amount of data emanating from social media have led to a profound interest in analyzing social media contents including posts, tweets, and instant messages among others to detect valence and emotions (Mohammad, 2016). Therefore, using a multi-theoretical framework, this work focuses on examining the immediate posts shared on Facebook by audiences after the grand finales of GMB 2017 and 2018. The study focuses on identifying the dominant issues that emerge out of the posts shared by the audiences, the emotions that come with them and significantly, how the winners have been portrayed in the posts. In trying to address the gap in the existing literature on beauty pageantry, especially within the local Ghanaian environment, three focal-point questions need to be addressed: what are the dominant issues that emerged from the posts shared by the audiences on GMB finale on Facebook? What kind of emotions do the audiences display through their posts? And, how were the beauty queens portrayed by the audiences through their posts?

This study, aside adding to the extant literature on audience engagement and beauty pageants in general also provides producers with the required knowledge about audience emotional behaviours especially in the production of media content. It also contributes to discourses on organization and production of beauty pageantry events, globally.

\section{Audience media engagement}

Globally, people constantly spend a huge amount of time with different forms of media. Most homes have become media rich with multiple media platforms including television, radio, game machines, and computers among others. In our everyday engagements, we draw upon and increasingly rely on information and ideas in space and time from the media. This engagement has heightened since the emergence of social media. Carmon (2014) argues that with the upsurge of social media, a great number of people have the opportunity to be either active or passive users of online consumption and production activities. Similarly, Arowolo (2017) avers that audience can be perceived from two perspectives: previously or traditionally as recipients with passive posture or as interactive and consultative audience in the communication process. With the inception of multiple communication channels, audiences have developed an increasing diverse and complex nature from being just mere listeners, spectators and consumers of media messages to dictating and shaping media content. Thus, audiences are no longer seen as mindless, ignorant undiscriminating, defenseless, and naïve or as manipulated or exploited by the media. This has described this new phenomenon as a concept of participation, empathy and entertainment that subsumes engaging with, talking about, sharing, judging and interpreting media content.

\section{Hans-Georg Gadamer's Hermeneutics}

Hermeneutics refers to the science or art of interpretation (Smythe \& Spence, 2012). Littlejohn and Foss (2011) also posit that interpretation is a part of our daily lives, hence, humans cannot exist without interpretation, as a result, our experiences and the world we interpret are so closely intertwined that they are virtually the same thing. Gadamer, Weinsheimer and Marshall (2013), however, contend that hermeneutics is not merely a science concerned with understanding and the interpretation of texts in relation to human experiences of the world in general, but as experiences which are inherently linguistic. Indubitably, language is the medium through which substantive understanding and agreement take place between two people. In effect, the commonality of language enables a shared acceptance of meaning and ability to vocalize thoughts either we engage in intra-personal or other forms of communication (Gadamer, 2004 as cited in Regan, 2012).

Therefore, one always understands and makes interpretation of a text from the perspective of presupposition or assumption of their socio- historical and cultural context. Thus, meanings we get are result of dialogue between our present day meaning and those embedded in the language of the text (Littlejohn \& Foss, 2011). In using this theory, we sought to understand the varied understanding and interpretations the audience of the GMB made of the phenomenon- that new understandings they generated through dialogue based on their experiential knowledge of the world.

\section{Reader response theory}

Reader response focuses mainly on readers and their relationship with the text to generate meaning (Lobo, 2013). A text is therefore meaningless except readers take it to mean many things. In short, the conveying of meaning is not an individual matter, rather an interpretive communication within interpretive communities where common meaning and realities are fabricated through social interaction (Littlejohn \& Foss, 2011).

Again, Fish (1980) as sited in Lobo (2013) points out, "there is no individualistic response to a text, but rather a product of the work of the interpretative community to which the reader belongs as a result of institutionalized assumptions established in the social group (p. 21)." Implicitly, an indication that meaning does not originate from a text, it is however solely dependent on the readers. Consequently, as these interpretative 
communities dictate the meaning the reader should make of a text, they in turn ask questions such as "What does a text do" not "What does the text mean" (Littlejohn \& Foss, 2011; p.134). Essentially, because meaning is generated as a result of interaction between the reader and the text in an interpretative community, interpretations can change throughout history, as their social constructs in relation to social, political and religious forces change, evolve, arise or disintegrate through the passage of time (Lobo, 2013). Babaee and Montashery (2012) argue that owing to the interpretative communities within which readers operate, readers have the opportunity to make any kind of judgment about their contemporary world and thus become the determiners of what is the truth, knowledge, and power of their life. Accordingly, this gives the upsurge to postmodernist era where there is no absolute truth

Fish Reader-Response is of the assumption that texts are open, in consequence, meanings are not situated in authorial intentions instead in a dynamic relationship out of the text with "the reader's expectations, projections, conclusions, judgments, and assumptions" (Babaee \& Montashery, 2012). In view of this, we examined, the role of the reader (viewers of GMB) in understanding the multiple perspectives they identify with the text, question whether readers passively consume the meaning presented to them by text or they actively made the meaning in relation to the text. Hence we further interrogate whether meaning and interpretation were solely a creation of the reader regardless of the influence of the text or circumstances.

\section{Theory of emotions}

Emotions and humans are inseparable. According to Ekman (1999), emotions are evolving adaptive values humans engage in to cope with fundamental life tasks. To Keltner (2004), emotions are a fundamental aspect of the way people shape their lives. At their very core, emotions are social and motivate thoughts and actions that are crucial to human relationships and interactions (Keltner \& Haidt, 2001). They are based on evaluations that are shaped by individual past experiences and different situations demand varied emotional reactions. Thus, the kind of emotion that would be exhibited by a person at a particular point in time is based on the evaluation the person makes and dependent on the current situation. Keltner, Ellsworth, and Edwards (1993) add by asserting that difference in emotions could lead people to construe situations in their own personalized ways based on a certain form of assessment.

In this study, therefore, we would be using Ekman and Friesen's (2003) six basic emotions: fear, anger, joy, sadness, disgust, and surprise. Undoubtedly and ideally, the six basic emotions theory focuses on facial expressions and usually utilized in interpersonal relationships. However, it has also been used by several scholars in detecting and analyzing emotions embedded in texts (Aman \& Szpakowicz, 2007; Alm, Rot \& Sproat, 2005; Holzman \& Pottenger, 2003; Wang, 2014). Aman and Szpakowicz (2007) and Wang (2014), for example, used annotated blog posts and Chinese news with Ekman's basic emotions. In similar vein, we adopted the precepts of Ekman and Friesen's six basic emotions to identify the emotions embedded in the posts shared by the audiences.

\section{Methodology}

Usually after the grand finale of GMB, audience storm social media to share their sentiments and emotions on the outcome of the results. Social media becomes replete with hundreds of posts, comments and likes on the pageant. This happens shortly after the winner has been declared and the broadcasting TV station shares post on their platform on the pageant. Facebook appears as the dominant social media platform where such posts are shared. The reason is that Facebook is the second most popular social media platform with $70.3 \%$ penetration in Ghana and second to WhatsApp with 83.9 (www.statista.com, 2020). This paper, therefore, conveniently uses Facebook as the social media sample for the research. Data was collected within $12 \mathrm{hrs}$ after the announcement of the winner of the beauty Pageant. The choice of this period is hinged on the premise that the passion, emotions and sentiments on the pageant shared by audiences would seem to have emerged during such periods when the event was still fresh in the minds of individuals and as such the display of outpour of emotions would be in their raw and natural state (Ofori-Birikorang, 2018). This could also generate some intentional and conscious communication (Girginova, 2013). In order to gather as much data as possible, a Facebook search with the hashtag \#GMB2017 and \#GMB2018 was used to download posts from the GMB Facebook pages. The search generated several posts relating to the event.

In all, 229 posts were sampled for the study comprising 8,438 words. The longest sampled post was made up of 147 words whilst the shortest post was 40 words. The posts did not include news on the event from mainstream news media houses shared on Facebook. The posts retrieved were stored in MS word document format and later converted into PDF. This was to prevent the posts from being altered and to avoid any inadvertent tampering of the raw data (Agboada \& Ofori-Birikorang, 2018). The unit of analysis was a 'post' and each one was accessed notwithstanding its length and considered a unique post worthy of analysis (Austamann, 2015; Girginova, 2013).

Cyber ethnography and content analysis were used for the study. Cyber ethnographic approach was used in order to get a deeper interpretation of the data collected from the posts and our immersion in the narratives to 
understand the interpretations and meanings the audiences brought to bear on the posts beyond the semantic content. Cyber ethnography was also chosen for this study because the data collected were retrieved from the virtual world and cyber ethnography presents itself as an appropriate strategy because within this space audience are able to interact freely with each other, share information, emotions and experiences (Akturan, 2009).

Qualitative content analysis was also used to elicit themes for the analysis and for easy interpretation (Hseih \& Shannon, 2005; Schreier, 2012). In line with the cyber-ethnographic research, we familiarized ourselves with the posts collected through careful iterative readings. We also produced verbatim posts in their original autography to ensure authentic and credibility of the data collected. In this regard, words and expressions as used by users in the posts were maintained in their original form, context, structure and language. There were several posts that had used code switching, pidgin expressions, and mixing Ghanaian language and English or pidgin expression in a single phrase or sentence to drive home their point. We reproduced the same expression in our coding book and, subsequently, in our analysis to reflect the originality and positionality of users in running commentary on the GMB event. Again, for the sake of emphasis, we have designated the names of the user in bold ink to delineate it form the post itself as some reproduction seemed to have jammed the poster of the message with the post.

Following Braun and Clarke's (2006) prescription analysis of qualitative data, we searched through the data looking out for patterns and meaning for easy thematic categorization and interpretation. Through this, we were able to generate themes based on the ideas that emerged from the close readings. The first and second research questions looked at unraveling the dominant issues that emerged from the prompt posts shared on the GMB finale and the emotional outpour of the users through their posts. Thus, through several interpretative works, the following diverse themes were generated: corruption, ethnocentrism, invective, theism, anger and disgust, surprise, sadness, and joy. Some of the themes were generated following Aman and Szpakowicz's (2007) approach for determining the emotional orientation of text by looking for obvious emotion words such as, "happy, sad, astonishment, surprise and the likes in a text. A third interrogating issue focused entirely on examining the representations of beauty queens through the posts by audiences. Themes derived include: commodification, intelligence and assertiveness, and fortitude.

\section{Findings and Discussion}

Results from the data collected from the social media platform-Facebook- were used to generate thematic categorizations of the dominant issues that emerged from the posts shared between 2017 and 2018. The data that were collected immediately after the Grand Finale of the GMB contest upon a declaration of the winner generated the following themes: corruption, invective, ethnocentrism, glorification and divination.

\section{Corruption}

A dominant thematic narrative that permeates the content of several of the posts shared was bribery and corruption. The data revealed that audiences perceived the pageant as characterized by robbery, theft and cheating. Out of revulsion for the outcome of the results, the users expressed their sentiments on how dishonest the decisions of the judges were. Deemed as unworthy, the users showed how fraudulent the actions of the judges, producers and all other stakeholders of the pageant have been since its inception. They described the judges as well as the entire pageant as corrupt. Some users posted:

Ameyaw Rashid: Eiii Serwaa paa 4th heeer TV3 mo y3 fokn. Since Baci won the GMB genuinely in 2014, all the successive winners are fixed. They don't deserve it. Corrupt TV3.

Kofi Sabasthon: Aah TV3 is a corrupt television in the world...how can u crown someone who don't deserve this...see some judges bi a just dey judge corrupt... I have stop watching tv3...apuuuu.

According to the users, the winners of the pageant had been crowned queens because the judges and producers had been bribed. This is further supported by the excerpts below:

Samuel Awotwe: OtooWhy should this pain others... Zeinab herself knew she doesn't deserve it but thanks to the judges who cooked it for her.

Pri Nce: Egocentrism and stupidity is why Ghana is still lacking ... This TV station will tell us that our politicians are corrupt ... Tv3 you are Super corrupt

Furthermore, they also argued that there were invisible hands behind the scenes of the pageant that manipulated the affairs of the pageant for their own gains. They manipulated the outcome by pushing money into the pageant in the form of sponsorship just to see their preferred contestant win. Ironically, these sentiments from users reveal that GMB rather than empowering women, seeks to dehumanize them by reducing them into objects and articles of commerce. The bodies of these beauty queens are used as advertising mediums to seek sponsorship and also source of revenue for the stakeholders rather than as mediums for promoting cultural heritage and empowerment. Johansson (1998) cited in Delfinado (2016) rightly puts this in the right perspective when he argues that "in consumer culture, the beautiful body is put at the center of symbolic production and the way we look becomes an image through which we see and understand ourselves" (p.12). The beauty and bodies of the women in this contest become the main project in capitalist consumerism, where the women are consumers and 
at the same time embodiments of the idealized femininity that is consumed (Johansson, 1998). This goes to affirm the argument of critics that beauty pageantry objectifies women as symbols and women bodies are used to promote commercial goods (King-O'Riain, 2008). By so doing it goes forward to affirm the assertion that beauty pageant is a status achievement for the capitalist ideals of the organizers.

\section{Ethnocentrism}

The use of ethnocentric expressions was another iterative theme that emerged out of the numerous posts shared by the users. This was a clear disregard for some ethical and ethnic propriety and, thus, defeats the purpose of showcasing the diverse and rich culture of the country. Just like all beauty pageants, GMB is an active platform for the production and contestation of cultural meanings and ideas (King-O'Riain, 2008; Koomson, 2016). On GMB, contestants have the opportunity of showcasing the various cultural traditions in Ghana, most importantly as a way of educating, informing and entertaining the public and by extension seeking for their support in terms of votes. The outcome of this is to define beauty to promote national unity. However, the purpose seems to have been lost as users through their posts shared their displeasure about the turn out of the pageant over the years. Recounting past experiences, users revealed how the pageant for years have favored certain groups of people to the disadvantage of others. They described the whole pageant as bias, partial and ethnocentric. One user said,

Margaret Manu: This can never be a reality show cuz all the judges $n$ organisers $r$ corrupt $n$ cheats. We will stop watching TV3 $n$ all your shows because you are all corrupt. The winner was so glaring but since Linda is an Easterner so she gave it to this undeserving Abena girl, kai.

Audiences, in shared posts, also referred to the some crowned queens as undeserving of their titles but nevertheless had emerged winners because of their ethnic background and the affiliation to the judges, producers and sponsors. Some other sentiments of users also indicated that such biases are due to the fact that some ethnic groups have historically been regarded as inferior to others. As seen in the post below and in clear ethnocentric tone, some users mentioned some particular ethnic groups as victims or perpetrators of this act:

ObremaKwameSelikemOkatakyie II: Tribalistic people go and ask your grandmother where your Ancestors came from Aboa bi gyi wo am half Northerner they are human beings one thing $i$ hate about some Akans is they talk bullshit you think Ghana belong to you go and ask your grandmother and she will tell you where you from learn some sense this modern day Tribalism has reach level all you know is fooling Daandulu wa it pain you go and sleep.

Interpretations of these excerpts illustrate how GMB, thus has become a site for ethnocentric effusions, and cultural imperialism, giving power to some dominant cultural groups over others.

\section{Invective}

Cyber observations conducted also revealed various forms of aspersions cast on the pageants. Some users condemned the producers, sponsors and judges of the pageant through the use of invectives. The posts shared carried various forms of insults and defamatory comments directed at the judges, producers and even the crowned queens to shame them for their actions. The decisions of the judges were seen as socially reprehensible and generated chastisements on both contestants and the judges. Some users, for example, scripted:

Lavish Smithn Zeinab !!!!,for the last time,I can't find my bed sheets ooh ,bring back my bed sheets, $i$ hope $u$ have not stolen that one self

Another said,

Gerrard Qwamena Sagoe: such imbecility of Tv3 is the reason why I watch Obonu tv only

Theism

Belief in the supernatural is an important aspect of the lives of most Ghanaians. People are ingrained in religious beliefs and practices that give meaning and essence to their lives (Acquah, 2011). All aspects of the lives of Ghanaians are infused with theological connotations. This belief in the supernatural was very much evident in the numerous posts that were shared on the pageant by users. Users attributed the achievements of the crowned queens to God/Allah. A post indicated:

Gideon Wiredu Kwesi: You are the best. When it was obvious hu de crown shud hv fallen on... God noes best $n$ it is He hu crowns.

Another post indicated:

Herty OffeiEve: if the devil hides $u$ under the earth and God saids u are a winner, u are a winner!! In as much as audiences were praising the winners for their performance and victory, they also imputed the victory to a supernatural being. Through most of the posts, users thanked God/Allah for granting their representatives victory and also fulfilling his promises in their lives. Undeniably, God, as the supreme diviner, became the determining factor for who the victor was and no one else. For example, one of the posts exalts the greatness of Allah:

Hamdia Abdul Rahaman: When you have Allah you have everything, so I didn't come to me as a shock Another also stated:

Hajia Fathoum If God says yes who can say no Zeinab becoming de winner is part if her destiny nd uf de Almighty has nt given a way she wouldn't be crowned so stp saying de judges switched everything 
It is important to acknowledge that users in sharing their sentiments on the 2017 and 2018 Grand finales were also recounting past experiences and these experiences helped them to make meaning out of the rulings of the pageant. Undoubtedly, most of the posts shared were reflections of things that had happened in the past and of which the users had come to understand through social interactions. It is, therefore, not so much surprising and out of place for some scholars to argue that in reading and interpreting texts, readers bring to bear their own experiences and ideologies just as argued in Fish's reader-response theory. According to the theory, reading is transactional and as readers engage texts, they construct meaning based on their own beliefs and experiences. The users actively engaged the text in its entirety, taking note of all the nitty-gritty linings of the pageant and making interpretations based on what had been experienced especially in the realm of their beliefs in a deity and the supernatural as indicated in the excerpt below:

$U$ worked hard for this and $u$ deserve the crown and also, $u$ have proven your enemies wrong that indeed, $u$ serve a living God who has already blessed $u$ from the day u were born. Long live, Abena

The users infused personal meanings into the text as they interacted with the text. This augments the idea of Reader-response theorists that the reader in making interpretations must be active and constantly building and synthesizing meaning, paying attention not only to the words on the page but also to images and emotions.

Just like the reader-response theory, these findings could equally be explained by the precepts of HansGadamer's philosophical hermeneutics. The theory contends that the meaning we make from texts is inevitably based on dialogue between our present day meaning and those embedded in the language of the text (Littlejohn \& Foss, 2011, p. 135). Individuals, therefore, always make interpretations from the perspective of presuppositions and assumptions. Thus, our individual experiences, histories and tradition give us ways of understanding a thing. To all appearances, the findings of the study revealed that the users engaged the text by bringing forth what they had experienced in the past, in relation to what is happening in the present to make interpretations. The responses to these interpretations, however, differed because of the different experiences of the users and the individual cultural context that directs the kind of interpretation that is made out of a text. The responses of the users through the posts shared indicated a diversity of audience interpretations varying with social and cultural context. Such diversity is understood as a sign of activity (Liebes \& Katz, 1990). A diversity of interpretations was found amongst audiences particularly between cultural and regional boundaries. Users whose candidates did not win had a very different interpretation of the pageant from those whose favourite contestant won. Amid the backlashes were glorifications and some form of satisfaction. Through the posts, the producers, pageants, and judges received admiration and commendation. One post read:

Bra Cletus D Sobrnen: Upper west representative wanted to spoil my mood for the whole year but thank God Zeinab intervened. You do al, my country girl.

Since meaning is generated as a result of interaction between the reader and the text in an interpretative community, interpretations can change throughout history, as their social constructs in relation to social, political and religious forces change, evolve, arise or disintegrate through the passage of time (Lobo, 2013). This reinforces Fish's (1980) argument that audiences are part of an interpretive community whose interpretive practices are guided by shared beliefs and cultural codes. Thus, the process of meaning making is a social act in which meaning is often negotiated and the reader always 'authors' the text. In short, the conveying of meaning is not an individual matter, rather an interpretive communication within interpretive communities where common meaning and realities are fabricated through social interaction (Littlejohn \& Foss, 2011). Fish (1980) as cited in Lobo (2013) points out "there is no individualistic response to a text, but rather a product of the work of the interpretative community to which the reader belongs as a result of institutionalized assumptions established in the social group (p.21)." Implicitly, this is an indication that meaning does not originate from a text, it is however solely dependent on the readers. Babaee and Montashery (2012) argue that owing to the interpretative communities, within which readers operate, readers have the opportunity to make any kind of judgment about their contemporary world and thus become the determiners of what is the truth, knowledge, and power of their life.

In sharing and making interpretations of the pageantry, there was also an outpour of emotions. Users showed various forms of emotions, including anger, disgust, sadness, happiness and surprise.

\section{Anger and disgust}

In most of the posts shared, common themes of distaste and disinterest toward the cultural show emerged. Users expressed their anger towards the judges, producers and the entire pageant. They showed a strong feeling of annoyance, displeasure and hostility. Many of the posts shared were very antagonistic and full of insults. A user posted:

EfvaKonamahMens: Tv3 don't ever come to BA again. We will never take part in this ur stupid beauty pageant again. With all this ur lies. Tell us something are we not beautiful. U guys should be very careful of wat $u r$ doing. U try coming here for any auditions $u$ will see for urself nonsense. No wonder Fancy Gadam was their performer... Total cheat. Cheaters nkoaa. Na U God is Watching $u$. Nana Kwesi Jnr De-One: Is time B/A stop attending this useless \#GMB\# 
Users were also disgusted about the final verdict of the judges. They were dissatisfied and as such expressed them through the posts shared. Evidently, users showed their disapproval of the rulings and as well considered the whole pageant as distasteful, unpleasant and sickening. One user stated,

Lydia Forson Tweaaa TV3, Linda Ampah de3 if she makes it to heaven dea, I'll lodge a complaint with Angel Michael p333.....thieves kmt $\odot \ominus 2$

\section{Sadness and surprises}

There were also moments of sadness inherent in some posts. Some portrayed elements of sorrow, loss and disappointment. Others communicated grief, regrets and despair towards the pageant through the posts. For instance, some stated:

John NeizarJnr: I'm sad paaaa. If zeinab win bcos of vote, the the purpose of ur program is nt realized. How did zeinab answer the questions? U have ended the program with shame

Rouleaux Royce GH: So why should I be voting next time?? Ohemaa won but you guys manipulated it with your $60 \%$ vote from the judges... There is no need for me to be voting if judges votes counts more than what I pay for. I've regretted paaaa..mtchew!!!

A critical analysis of the posts shared also revealed elements of surprises. Some users were startled and astonished with the results of the event. Some of the posts included:

Comfort Baa Am surprised but I was not the judge. Any way congrats Zeinab. I pray that your flight against maternal mortality will will be successful. God bless Ghana.

Sedem Badasu We saw it coming! People said it but I doubt it. It's only in Ghana we will know who will win a competition before we start. And Judges have their favourite contestants! We all saw it that there is no special expertise used by the judges. Just like last year, the bias continues...

Through the shared posts, it could be deduced that the decisions of the judges were unexpected and came as a surprise to the users after living through those moments of suspense while waiting for the declaration of results.

Joy

Most of the audience also expressed their intense joy towards the pageant. Through the posts, they showed their satisfaction on the final judgment of the pageant. The posts were full of cheerful and pleasurable sentiments. In expressing joy, some users posted:

Amenyo Patience: I can't even control my tears. I love you Abena, am happppppyyyyy my God, someone wake me up. Wooooooooow.

Davani Dodoo: I dont envy her at all. First time watching the programme and she impressed me from start to finish. I tipped her to win and am happy! Am a tuesday born toooo! You go girl!!! U deserve it! Congrats

This post signifies how exhilarated the user was in seeing her contestant win the crown. The user was very much pleased with the results, and shared the post to indicate her joy and satisfaction. Undoubtedly, the joyful emotions manifested were hinged not only on the current outcome of the pageant but based on already existing feelings and past predispositions on the pageant. As has been argued earlier, emotions are based on evaluations that are shaped by individual past experiences, it is obvious that the emotions exhibited in the posts by the audiences were due to the evaluations and assessments that the audiences had made since the emergence of the pageant. More importantly, the multiplicity of the emotions was as a result of the specific individual evaluations and interpretations they had brought to bear. It was also dependent on the current circumstances and position in which the audiences found themselves to reinforcing the idea that, different situations would demand varied emotional responses. Another important issue that became the focus of this study was the representation of the beauty queens by the audiences through the posts. The data collected generated four main themes: commodification, heroism, intelligence and assertiveness, and purposefulness.

\section{Commodification}

Media theorists are of the idea that media can play a significant role in either perpetuating or challenging social norms and behavior. It can also reinforce gender-based discrimination by representing stereotypical images of women or providing a portrayal that empowers while exposing acts of gender bias. New media in particular have become a platform for the objectification of women and girls from everyday hyper- sexualized, one-dimensional image of women and girls to overt violence (Hamashima, 2012). This was evidently present in the various narratives shared on the Facebook walls of the 2017/2018 GMB, as users (audiences) incessantly commodified the bodies of the women. Much emphasis was put on their physical appearance and beauty. Whereas some dwelled on their pretty and photogenic physical features, others also focused on likening them to infidels and inanimate objects such as food. Thus, most of the users sought to embrace an outmoded sexist culture that limits women to things and commodify their body parts. One user wrote:

Grande Master H. Amoako: Awam!!! Nana was the Candy that deserves licking!

In the above post, the user, rather than commending the said queen on her performance and achievement, sought to commodify her.

Another post indicated: 
ABENA was too hot for her competitors.

Such portrayals, according to radical feminist theorists, commodify women and limit their abilities and capacities as individuals and consequently, dehumanize them. It also goes to affirm the argument of Hamashima (2012) that new media have become a platform for the objectification of women and girls. More so, beauty pageant in its entirety objectifies women and foster sense of insecurity. Just as argued by feminist theorists that beauty contests reinforce the patriarchal system and hegemonic femininity through the objectification, control and commoditization of the body of women (Banet-Weiser, 1999).

\section{Intelligence and assertiveness}

Over the years, Beauty Pageants have gradually moved from physical beauty to become more inclusive of other issues to broader concentration on scholarship and education, cultural preservation, cultural awareness, gender equality, health, as well as any other cause that is geared towards empowerment and deemed beneficial to stakeholder communities (Hamashima, 2012). Being crowned a queen in a beauty contest, therefore, is based on one's ability to please both audiences and the judges. This requires articulacy and having full grasp of ongoing discourses on social, political, economic and cultural issues. Just like all pageants, contestants of GMB through their weekly performances are expected to impress audiences and judges by informing, educating and entertaining them on their respective culture and traditions and how best social issues within their communities could be easily tackled. The ladies who participate in this reality show are required to depict the unique traditional culture and values related to the various ethnic groups of the regions they represent in Ghana, with the aim of promoting national unity among the regions and its peoples (Koomson, 2016). Evidently, this was very much exemplified by the queens as the users incessantly referred to them as intelligent and assertive. Through the shared post, users described the queens as knowledgeable, well -informed and apt and brainy. Users were very much enthused about their performances and the debt of knowledge they shared during the entire weeks of the pageant. One user stated:

M Rabiu Abubakar: Just to contribute, I would say all the girls were intelligent especially Zainab and Baaba. Zainab's performance although criticized was the best. But her answer to the last question was too brieffor my liking, yet on point.

Another also said:

Herty Offei: Look, this girl has made most of the girls from Ghana learn a lot. She is brave, intelligent, confident, etc. She is the youngest and has bigger and larger goal...

Users sometimes cocooned themselves joyfully by expressing how impressive some contestants have been through a display of energy and eloquence as revealed in the post below:

Akosua Oforiwaa Amoako: Abena worked for this. She has d energy,vry eloquent $n$ has the charisma too. Yes d judges liked her buh chly d gal is gud hands dwn...Ohemaa wz equally gud but chly Abena Fortitude

has the crowd -2

Cyber observations conducted on Facebook through the posts shared also described the beauty queens as determined and focused. According to users, the beauty queens were resolute and strong-willed throughout the competition and that propelled them into achieving such great heights. Users commented on the consistency of the beauty queens as well as their tenacity. This point is mirrored in some selected posts shared:

NaanaAmoakoAgyemang U go girl!!! Abena has been consistent from Day 1. She worked for it $n$ got results congratulations Girl congrats to Ohemaa as well

Nanavaw Amoako: She deserved it. She's persevered until emerging victorious. Congratulations \#Abena

Agvarkwa Victoria Oduro: Gal u deserve it hard work pays

In several instances the beauty queens were depicted as empowered and eloquent, especially for their ability to perform before huge audience to showcase their respective cultural traditions. One user shared:

BukariIshawTaabavala: Zeinab, thank $u$ for making $u$ s proud and $u$ actually deserves to be the queen amongst the queens from ur eloquent, spectaculars and fantastic envisage of the GMB 2017. We will all rally behind $u$ and ur project to make it productive to the good people of Ghana.

Another also described some of the beauty queens in a hail of exalted expressions including describing a winner as "beauty with brains":

Alberta Asante Yeboah: Abena is the 2018 queen all hail the pretty queen \#3pueimantanmu nsroma 3 fata wo Abena \#proudEasternerflower papabi beauty with brains.

Through the posts shared, audiences admired the beauty queens for their fortitude and outstanding performances. They were raised to the status of heroines for bringing grace to their respective cultures. Some were referred to as queen of queens for the seemingly iconic achievements and newly achieved status.

\section{Conclusion}

This study sought out to interrogate the posts that were shared by users of Facebook on the 2017 and 2018 Grand 
Finales of Ghana's Most Beautiful. The study was hinged on three main objectives: to identify the dominant issues that emerged from the prompt posts shared by audiences on the GMB finale on Facebook, to examine the emotional outpour of the audiences through the posts and to examine how the beauty queens were represented by the audiences through the posts. The study reveals that through the outpour of anger, disgust, sadness, surprises, and joy audience raised issues of corruption, invectives, ethnocentrism, commodification, and theism through the posts shared. Again, the study also found that the beauty queens were represented as commodities, intelligent, assertive and filled with fortitude. These findings present GMB as a paradox of event seeded in elements of empowerment, oppression, corruption, ethnocentrism and joy. GMB, thus, seems to have deviated from its purpose of empowering women and promoting national unity among the various regions by morphing into an arena for inciting ethnic feud a site of oppression. While the pageant is presented as an event of skills and talent, money and physical appearance have become huge lubricants in the determination of the ultimate goals of the event. Focusing on the appearance of women and putting them in a competitive display to determine the best reinforces the public gaze theory and further positions them in the confines of capitalism where the principle of competition is utilized and upheld. In this context, contestants are challenged just as argued by Cohen, Wilk and Stoeltje (1996) to catch up to the ideal image of beauty promoted by the organizers with a capitalist lens. This kind of control and imposition on their bodies force beauty into a narrow and skewed mold and further, reinforces the idea that beauty pageants are sites where women are sexualized and reduced to objectified commodities.

We, therefore, conclude based on the implications of the findings that organizers of GMB consider a total restructuring of the pageant into one that embraces cultural differences and devoid of corruption and oppression of women. They should also be very much interested in the sentiments and feedback from audiences as the findings debunk the long-held beliefs and assumptions that audience (users) are victims of ideological hegemony. We must understand that textual meaning is produced through an interaction between text and audience and that audiences do not passively consume the meaning presented to them by an objective literary text; rather, they actively engage it to make meaning. Also, audiences differently interprete and make sense of what they read and view based on their presuppositions, cultural, and historical contexts, background or cultural positioning.

\section{References}

Acquah, F. (2011). The Impact of African Traditional Religious Beliefs and Cultural Values on ChristianMuslim Relations in Ghana from 1920 through the Present: A Case Study of Nkusukum-Ekumfi-Enyan area of the Central Region (Doctoral Thesis). University of Exeter. Retrieved https://ore.exeter.ac.uk/repository/bitstream/handle/10036/3473/AcquahF.pdf

Agboada, D. J.\& Ofori-Birikorang, A. (2018). Self-Branding, Identity construction and Social Media Use by Chief Executive officers in Ghana. New Media and Mass Communication, 67, 68-80

Ahmed-Ghosh, H. (2003). Writing the nation on the beauty queen's body: Implications for a "Hindu" nation. Meridians, 4(1), 205-227.

Akturan, U. (2009). A review of cyber ethnographic research: A research technique to analyse virtual consumer communities. Bogazici Journal 23(1-2), 1-18.

Alm, C. O., Roth, D., \& Sproat, R. (2005). Emotions from text: machine learning for text-based emotion prediction. In Proceedings of human language technology conference and conference on empirical methods in natural language processing. 579-586. Retrieved from https://www.aclweb.org/anthology/H05-1073.pdf

https://citeseerx.ist.psu.edu/viewdoc/download?doi=10.1.1.1081.5218\&rep=rep1\&type=pdf

Aman, S., \& Szpakowicz, S. (2007). Identifying Expressions of Emotion in Text. In International Conference on Text, Speech and Dialogue. (196-205. Springer, Berlin, Heidelberg.

Arowolo, S. O. (2017). Media Audience: The Unending Swing of the Pendulum. Retrieved from https://www.researchgate.net/publication/320978021

Austamann, J. R. (2015). From fat cats to cool cats? CEOs and micro-celebrity practices on twitter (Unpublished Master's thesis, London school of Economics, University of London).

Babaee, R., \& Montashery, I. (2012). Stanley Fish with respect to the reader. International Journal of English and Literature, 3(2), 18-24.

Balogun, O. M. (2012). Cultural and cosmopolitan: Idealized femininity and embodied nationalism in Nigerian beauty pageants. Gender \& Society, 26(3), 357-381.

Banet-Weiser, S. (1999). The most beautiful girl in the world: Beauty pageants and national identity. University of California Press.

Barnes, N. B. (1994). Face of the nation: Race, nationalisms and identities in Jamaican beauty pageants. The Massachusetts Review, 35(3/4), 471-492.

Braun, V., \& Clarke, V. (2006). Using thematic analysis in psychology. Qualitative Research in Psychology, 3(2) (ISSN1478-0887), 77-101.

Carmon, D. (2014). Where is the audience? Testing the audience reception of non-professional subtitling. 
Translation research projects, 5, 77-92. Retrieved from: https://www.researchgate.net/publication/268485198

Cohen, C. B., Wilk, R., \& Stoeltje, B. (1996). Beauty queens on the global stage: Gender, contests and power. New York. Routledge.

Crawford, M., Kerwin, G., Gurung, A., Khati, D., Jha, P., \& Regmi, A. C. (2008). Globalizing beauty: Attitudes toward beauty pageants among Nepali women. Feminism \& Psychology, 18(1), 61-86.

Delfinado, V. G. C. (2016). Beyond the sash and the crown (Doctoral dissertation, University of the Philippines Manila).

Dennis, A. (2018). Promoting Ghana's traditional cultural aesthetics in Ghana's most beautiful reality television show. Legon Journal of the Humanities, 29(2), 176-196.

Ekman, P. (1999). Facial expressions. Handbook of cognition and emotion, 16(301), e320. Retrieved from: https://www.paulekman.com >pdf.

Ekman, P., \& Friesen, W. V. (2003). Unmasking the face: A guide to recognizing emotions from facial clues, 10. Ishk.

Fish, S. E. (1980). Is there a text in this class?: The authority of interpretive communications. Cambridge: Harvard University Press.

Gadamer, H. G., Weinsheimer, J., \& Marshall, D. G. (2013). Truth and method. London: Bloomsbury.

Girginova, K. (2013). Social CEOs: Twitter as a constitutive form of communication. (Unpublished Master's Thesis, Georgetown University).

Hamashima, M. (2012). Beauty in the indigenous pageant: The cultural and social relevance of Miss Samoa. Independent Study Project (ISP) Collection, 1486.

Hinjosa, M., \& Carle, J. (2016). From miss world to world leader: Beauty queens, paths to power, and political representations. Journal of Women, Politics \& Policy, 37(1), 24-46.

Holzman, L. E., \& Pottenger, W. M. (2003). Classification of emotions in internet chat: An application of machine learning using speech phonemes. Technical Report, Leigh University.

Hseih, H. F., \& Shannon, S. E. (2005). Three approaches to qualitative content analysis. Qualitative health research, 15(9), 1277-1288.

Johansson, P. (1998). Chinese women and consumer culture: Discourses on beauty and identity in advertising and women's magazines, 1985-1995. Stockholm: Stockholm Universitet.

Keltner, D. (2004). Ekman, emotional expression, and the art of empirical epiphany. Journal of Research in Personality, 38(1), 37-44. doi:10.1016/j.jrp.2003.09.006

Keltner, D., Ellsworth, P. C., \& Edwards, K. (1993). Beyond simple pessimism: Effects of sadness and anger on social perception. Journal of personality and social psychology, 64(5), 740. doi=10.1.1.480.158

Keltner, D., \& Haidt, J. (2001). Social functions of emotions. In T. Mayne \& T. Bonanno (Eds.),

Emotions: Current issue and future directions. New York: Guilford Press.

King - O'Riain, R. C. (2008). Making the perfect queen: The cultural production of identities in beauty pageants. Sociology Compass, 2(1), 74-83.

Koomson, S. (2016). Set Design with Adinkra Symbols for Tv3‘s Ghana’s Most Beautiful 2014. (Doctoral dissertation, University of Ghana). Retrieved from http://ugspace.ug.edu.gh/

Labo, A. G. (2013). Reader-Response Theory: A Path Towards Wolfgang Iser. Letras, (54), 13-30.

Liebes, T., \& Katz, E. (1990). The export of meaning: Cross-cultural readings of Dallas. New York: Oxford Univ. Press. [ISBN: 9780195054873]

Littlejohn, S. W., \& Foss, K. A. (2011). Theories of Human Communication. Long Grove, IL. Waveland Press, Inc.

Lukes, C. A. (2010). Social media. AAOHN Journal, 58(10), 415-417. Retrieved from

https://journals.sagepub.com/doi/pdf/10.1177/216507991005801002

Mohammad, S. M. (2016). Sentiment analysis: Detecting valence, emotions, and other affectual states from text. In Emotion measurement, 201-237. Woodhead Publishing

Ofori-Birikorang, A. (2018). Communicating death that matters: Facebook posthumous micro-celebrity construction of a Captain's identity and violent death. Inter University Conference for Doctoral Studies Journal of Research Findings, Vol. 1. No2, p. 203-240 ISSN 2667-0800

Oza, R. (2001). Showcasing India: Gender, geography, and globalization. Signs. Journal of Women in Culture and Society, 26(4), 1067-1095.

Regan, P. (2012). Hans-Georg Gadamer's philosophical hermeneutics: Concepts of reading, understanding and interpretation. Meta: Research in hermeneutics, phenomenology, and practical philosophy, 4(2), $286-303$.

Schreier, M. (2012). Qualitative content analysis in practice. Sage publications.

Smythe, E., \& Spence, D. (2012). Re-viewing literature in hermeneutic research. International Journal of Qualitative Methods, 11(1), 12-25. Retrieved from: https://journals.sagepub.com/doi/pdf/10.1177/160940691201100102 
Statista, (2020). Leading social media platforms in Ghana 2020. Retrieved on August 20, 2021 from: http://www.statista.com

Wang, Z. (2014). Segment-based fine-grained emotion detection for Chinese text. In Proceedings of the Third CIPS-SIGHAN Joint Conference on Chinese Language Processing, 52-60.

\section{Authors}

Andy Ofori-Birikorang is an Associate Professor in the School of Communication and Media Studies, University of Education Winneba

Ama Boatemaa Appiah-Kubi is a doctoral student at the Cathy Hughes Scholl of Communication, Culture and Media Studies, Howard University

Akosua Asantewaa Anane is an Assistant Lecturer and a doctoral student in the School of Communication and Media Studies, University of Education, Winneba

Yvonne Dedzo is an Assistant Lecturer and a doctoral student in the School of Communication and Media Studies, University of Education, Winneba 